Annals of International Medical and Dental Research

E-ISSN: 2395-2822 | P-ISSN: 2395-2814

Vol-8, Issue-1 | January-February 2022

DOI: $10.53339 /$ aimdr.2022.8.1.30

Page no- 225-234 | Section- Research Article (Obstetrics and Gynecology)

\title{
Treatment of Infertility in Women with Polycystic Ovary Syndrome in a Single Center Study
}

\section{Rehena Nasreen $^{1 *}$, Mohammad Kamrul Islam², Sumon Kumar Sen ${ }^{3}$, Md. Mahamudul Hasan ${ }^{4}$}

${ }^{1}$ Medical Officer, Department of Obstetrics and Gynecology, Dhaka Medical College Hospital, Dhaka, Bangladesh.

Email: rehenanasrin82@gmail.com Orcid ID: 0000-0001-9612-5809

2Rasident, Department of Urology, Bangabandhu Sheikh Mujib Medical University, Dhaka, Bangladesh.

Email: medicheque@gmail.com Orcid ID: 0000-0003-2879-4570

${ }^{3}$ Consultant, Department of Surgery, Central Police Hospital, Dhaka, Bangladesh.

Email: drsksen415@gmail.com

Orcid ID: 0000-0003-3480-1300

${ }^{4}$ Junior Consultant, Department of Surgery, Bangabandhu Sheikh Mujib Medical University, Dhaka, Bangladesh.

Email: drmhpannu@gmail.com

Orcid ID: 0000-0002-8915-3243

${ }^{*}$ Corresponding author

Received: 08 October 2021

Revised: 19 November 2021

Accepted: 30 November 2021

Published: 22 December 2021

\begin{abstract}
Background: Anovulatory infertility is caused by polycystic ovarian syndrome in 80 percent of patients. Preconception guidelines, such as lifestyle modification (weight loss) to avoid fetal neural tube abnormalities, and quitting smoking and drinking alcohol, are all part of the early treatment. A clomiphene citrate medication for timed intercourse is the first-line pharmacological treatment for producing ovulation. Exogenous gonadotropins or laparoscopic ovarian surgery are two options for second-line pharmaceutical treatment (ovarian drilling). Ovulation induction using clomiphene citrate or gonadotropins is effective, with a $70 \%$ cumulative live birth rate. When laparoscopy is necessary, ovarian drilling should be done; this operation is usually successful in around half of the instances. Finally, when the previous interventions have failed, a high-complexity reproduction treatment (in vitro fertilization or intracytoplasmic sperm injection) is recommended. There is no evidence that metformin should be used routinely in the treatment of infertility in anovulatory women with polycystic ovary syndrome. Aromatase inhibitors show promise, but more research is needed to confirm their safety. Methods: This study was conducted in Department of gynecology and obstetrics, Dhaka Medical College Hospital, Dhaka, from January 2019 to December 2019. A total number of 100 patients with multiple myeloma were analyzed cytogenetically by interphase fluorescence in situ hybridization (iFISH). The collected data were analyzed by using the Statistical Package for Social Science (SPSS-24) for windows version 24.0. Conclusion: PCOS is a frequent syndrome and the most frequent cause of infertility. PCOS is defined as a syndrome with at least two of three of the Rotterdam criteria. A complete evaluation of the infertility is needed to exclude other causes of infertility..
\end{abstract}

Keywords:- Polycystic Ovary Syndrome; Infertility; Clomiphene Citrate; Ovarian Drilling; In Vitro Fertilization..

\section{INTRODUCTION}

Polycystic ovarian syndrome (PCOS) is an endocrine and reproductive condition that affects between $5 \%$ and $13 \%$ of women of reproductive age. PCOS is the most common cause of hyperandrogenism and oligoanovulation in women of reproductive age, and it's linked to infertility as well as clinical

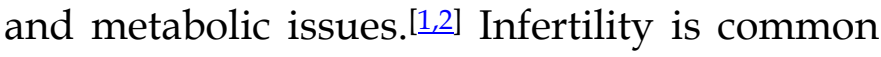
in women with PCOS, ranging from 70 to $80 \%$. The evaluation of infertility in women with 
Annals of International Medical and Dental Research

E-ISSN: 2395-2822 | P-ISSN: 2395-2814

Vol-8, Issue-1 | January-February 2022

DOI: 10.53339 /aimdr.2022.8.1.30

Page no- 225-234 | Section- Research Article (Obstetrics and Gynecology)

PCOS or other causes of subfertility should begin after six months of unsuccessful pregnancy attempts if the couple has regular sexual intercourse (2 to 3 times/week) without using contraceptive methods, according to the American Society for Reproductive Medicine.[3] Evaluations of tubal patency (hysterosalpingography or laparoscopy with chromotubation) and semen analysis (spermogram) are required before deciding on treatment for infertile women with PCOS in order to maximize the success of the medication. Tubal patency testing, on the other hand, may not be required before starting clomiphene citrate (CC) medication. A tubal patency examination becomes required prior to commencing the therapeutic treatment of infertility if a patient is resistant to this medicine, requires gonadotropins, or presents with additional reasons of infertility.[4] Preconception counseling and the use of medications to induce mono or bifollicular ovulation are the mainstays of infertility treatment. Other therapeutic methods, such as exogenous gonadotropins or laparoscopic ovarian drilling, which are considered secondline therapy, or in vitro fertilization (IVF), which is considered a third-line treatment, may be used as well.[5] As a result, the most appropriate treatment is determined by the patient's age, the presence of other infertilityrelated issues, previous treatment experience and length, and the couple's level of concern.

\section{Evaluation of infertility in PCOS patients}

Evaluation of infertility (or subfertility) is recommended after 12 months without pregnancy in couples having regular sexual intercourse (2 or 3 times/week). [1] PCOS is the first cause of female infertility but the definite diagnosis should be given after exclusion of other etiologies of infertility such as other endocrine disorders (thyroid dysfunction, hyperprolactinemia, congenital adrenal hyperplasia, Cushing syndrome, premature ovarian insufficiency), anatomical dysfunctions (endometriosis, pelvic inflammatory diseases,) or iatrogenic causes (surgery, chemotherapy, radiations). The patient's personal medical and surgical as well as familial history, followed by a complete physical and gynecological examination is mandatory when exploring infertility. A thorough table with the infertility factors to search can be found in the supplemental data. Additional diagnostic tests including blood samples, ultrasonography and hysteroscopy among others are recommended. Anti-müllerian hormone $(\mathrm{AMH})$ is a useful test in the evaluation of infertility. It is produced by granulosa cells of early follicles and helps to evaluate the ovarian reserve. Because its production is gonadotrophin-independent, AMH levels remain consistent during the menstrual cycle.[1] Women with PCOS present AMH levels 2 to 3 folds higher than non-PCOS women because of an increased number of preantral and small antral follicles. The increased AMH level seems correlated with the severity of PCOS.[6] Transvaginal ultrasonography (TVUS) will evaluate the antral follicle count, endometrium thickness and diagnose uterine anomaly (polyps, myomas and congenital malformation).

\section{Treatment}

Non-pharmacologic measures remain the first line and the most effective in the treatment of infertility. We already know the positive effects of clomiphene citrate letrozole and gonadotropins in the treatment of infertility in 
Annals of International Medical and Dental Research

E-ISSN: 2395-2822 | P-ISSN: 2395-2814

Vol-8, Issue-1 | January-February 2022

DOI: $10.53339 /$ aimdr.2022.8.1.30

Page no- 225-234 | Section- Research Article (Obstetrics and Gynecology)

PCOS. Myo-inositol and ovarian drilling are new lines of therapeutic and will be discussed in this review. This review includes articles until March 2021.

\section{Non-pharmacological measures}

Lifestyle changes are the first line of treatment for women with PCOS. In all cases, smoking should be ceased and physical exercise encouraged. Weight loss is recommended in overweight and obese women. [7]

Several studies have shown that a 5 to $10 \%$ weight loss in overweight and obese women may be sufficient to restore regular menstruation and ovulation. $[2,8,9]$ This weight loss also enhances the effect of the ovulationinducing agents. Altogether, weight loss in obese women with PCOS improves pregnancy rate in addition to the known metabolic benefits. [10] Bariatric surgery can be considered when BMI is above $35 \mathrm{~kg} / \mathrm{m} 2$ and lifestyle changes conducted for more than 1 year have failed.[11] A meta-analysis showed that obese women suffering from PCOS with bariatric surgery presented a significant decrease in testosterone levels associated with a resolution of hirsutism in $53 \%$ and of menstrual irregularities in $96 \%$ of the subjects.[12] However, there is currently no strong evidence suggesting that bariatric surgery improves the pregnancy rate in women with PCOS. Moreover, surgical complications, intestinal incarceration in Petersen space and lack of vitamins should not be neglected. $[\underline{13,14]}$

\section{Pharmacological measures}

\section{Metformin}

Due to the key role of insulin resistance in PCOS, off-label use of metformin (an insulin sensitizer) has been considered as a first-line treatment for PCOS for many years. Several studies have suggested that metformin (alone or in association with Clomiphene) increased ovulatory cycles in women with PCOS.[15] However, pooled analyses also showed that it does not increase the live birth rate.[16,17] Therefore, the current guidelines do not recommend the use of metformin for ovulation induction and limit the use of this drug to insulin resistance in PCOS and type 2 diabetes.[]

\section{Treatment already confirmed}

\section{First line of treatment}

\section{Clomiphene citrate}

Clomiphene citrate $(\mathrm{CC})$ remains the first-line ovulation induction drug in women with PCOS suffering from infertility.[15] $C C$ is an anti-estrogen therapy that blocks estrogen receptors in the hypothalamus and, with the negative feedback mechanism, leads to a stimulation of the follicular development.[5,13,18] Administration of CC has to be monitored (by ultrasound and endocrine blood sample) to appreciate the day of the ovulation and to prevent multiple pregnancies (rate of $11 \%$ risk). $[20,21,22,23]$ As monitoring, ultrasound evaluation is done on days 11 to 14 , and measures of the follicular growth and endometrial thickness are also performed. $[\underline{20,21,22,23]}$ 
Annals of International Medical and Dental Research

E-ISSN: 2395-2822 | P-ISSN: 2395-2814

Vol-8, Issue-1 | January-February 2022

DOI: 10.53339/aimdr.2022.8.1.30

Page no- 225-234 | Section- Research Article (Obstetrics and Gynecology)

\section{Letrozole}

Letrozole is a member of the aromatase inhibitors family. Aromatase inhibitors result in lower E2 levels. This strongly reduces the risk of multiple follicle development. This is one of the main advantages of letrozole among $\mathrm{CC}$. The other advantage is that letrozole does not affect endometrial estrogen receptors, and therefore does not exert any deleterious effect on endometrial thickness and cervical mucus.[24,25] Mejia and al suggest a higher ovulation rate with letrozole but there is no evidence of a higher pregnancy rate with this therapy However, recommendations remain that letrozole is a second-line of treatment for women who have CC resistance or failure without another infertility factor. [26,27]

\section{Second line therapeutic options: gonadotropin therapy}

A second-line therapeutic option is gonadotropin therapy associated with timed intercourse. For women with PCOS, all recommendations now agree to use a low-dose step-up regimen to prevent ovarian hyperstimulation syndrome (OHSS) and multiple pregnancies. The high number of antral follicles in women with PCOS predispose them to develop OHSS. [28,29]

\section{Ovarian drilling}

An alternative treatment is laparoscopic or transvaginal ovarian drilling, also called ovarian diathermy or electrocoagulation. It acts as a second line of treatment. Indeed, this technique can be proposed after 4 to 6 cycles of $\mathrm{CC}$ and before treatment with gonadotrophins [5]. Ovarian drilling is a technique consisting of puncturing the ovaries. The aim of the technique is to penetrate the ovarian capsule with an electrosurgical probe at a number of points ( 3 to 6 punctures). Each point measuring $4 \mathrm{~mm}$ in diameter and $5-7 \mathrm{~mm}$ in-depth and the duration of the penetration is $5 \mathrm{~s}$. This technique replaces cuneiform resection of the ovaries. Cuneiform resection leads to adherences and surgical complications and was performed before the beginning of the ovarian drilling technique. [37]

The first laparoscopic ovarian drilling was performed in 1984 and the first transvaginal laparoscopy in 2001. Both techniques can be used.[38,39]

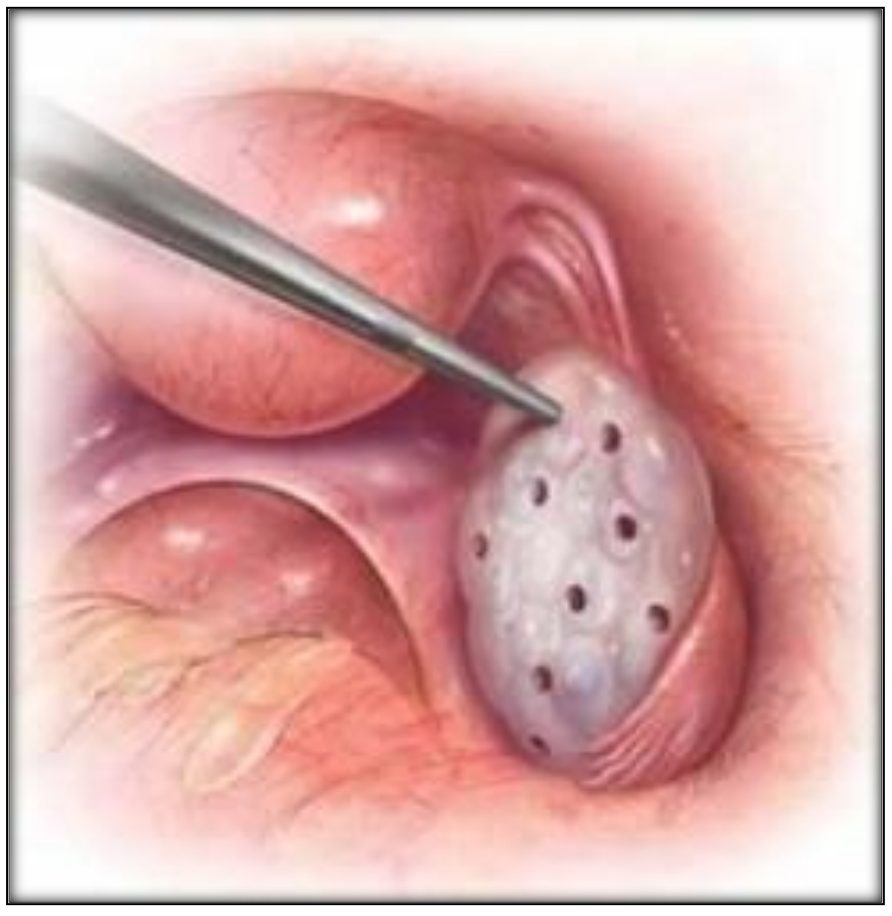

Figure 1: Laparoscopic surgery of ovarian drilling.

\section{Technique}

Laparoscopic ovarian cautery is performed with a traditional endoscope and two 
Annals of International Medical and Dental Research

E-ISSN: 2395-2822 | P-ISSN: 2395-2814

Vol-8, Issue-1 | January-February 2022

DOI: 10.53339 /aimdr.2022.8.1.30

Page no- 225-234 | Section- Research Article (Obstetrics and Gynecology)

additional trocars. The whole length of the unipolar needle electrode is inserted into the ovary with a setting of $40 \mathrm{~W}$ for $4-5 \mathrm{~s}$. The laparoscopic technique is the recommended procedure for ovarian drilling.

Transvaginal hydrolaparoscopy is performed with saline solution in the peritoneal cavity. The endoscope has an angle of 30 degrees and permits examination of the entire pelvic cavity.

Salpingoscopy with fallopian tube and fimbriae inspection can also be performed by transvaginal laparoscopy (THL). [40] Bilateral ovarian drilling was performed, with about 10 perforations in each ovary and a depth of insertion of $10 \mathrm{~mm}$. This technique can be realized with spinal anesthesia. [41]

The risks associated with ovarian drilling are those linked to any surgical procedure and the risk of creating adhesion. The choice of the technique (laparoscopy versus THL) may influence safety. Giampaolino et al. compared the benefits of laparoscopy versus THL.[40] Results showed that THL is faster, reduces adhesions, and is better tolerated by the patients (less post-operative pain). The mechanisms of these benefits could be the installation of saline solution, the shorter duration, the use of bipolar diathermy and the reduction of bleeding due to lower manipulation of the ovaries than during a laparoscopy.

THL is also an easier approach for women with obesity. [40,42] Finally, Giampaolino et al. also suggest that the learning curve with THL is shorter than with laparoscopy.

Nevertheless, the risk of this technique is a perforation of the rectum, (0.5\% risk). [43] Should this happen, it is usually managed by conservative treatment and antibiotics. A second-look laparoscopy will be performed to confirm the peritoneal integrity.

\section{Mechanism of action}

The mechanism of action of ovarian drilling is still poorly understood. It seems that ovarian drilling impairs local androgen synthesis and reduces intraovarian androgen level which decreases the inhibitory effect on follicular maturation. Lower levels of androgens diminish the peripheral conversion of androgen to estrogen and decrease the positive feedback on LH secretion. Recruitment of new follicles is permitted spontaneously or with exogenous FSH stimulation.[44]

This technique improves hirsutism and acne, irregular cycles, the occurrence of ovulation and pregnancy. ${ }^{[41,45]}$

Ovarian drilling does not require the monitoring of ultrasound and avoids the risk of multiple pregnancies or OHSS. [41] In 2020, a Cochrane review showed moderate-quality evidence that laparoscopic ovarian drilling probably reduces the number of multiple pregnancies and may result in less OHSS. [46]

The efficacy of ovarian drilling is variable in the literature. Ovulation and pregnancy rates of 30 to $90 \%$ and 13 to $80 \%$, respectively, have been reported.[47] Factors increasing the efficacy of the technique are high LH concentration (>10UI/1), short infertility duration ( $<3$ years), age ( $<35$ years) and low antral follicle count $(<50)$. [47] High BMI $(>35 \mathrm{~kg} / \mathrm{m} 2)$, insulin resistance and high testosterone concentration are negative factors for the effectiveness of this treatment.[41] 
Annals of International Medical and Dental Research

E-ISSN: 2395-2822 | P-ISSN: 2395-2814

Vol-8, Issue-1 | January-February 2022

DOI: $10.53339 /$ aimdr.2022.8.1.30

Page no- 225-234 | Section- Research Article (Obstetrics and Gynecology)

The choice of the technique may also influence the results. In the first 6 months following THL, Giampaolino et al. demonstrated in 2018 that ovulation occurred in $82.9 \%$ of the patients associated with a pregnancy rate of $70 \% . \underline{41}]$

Besides its efficacy in terms of pregnancy rate, the other big advantage of ovarian drilling is the long-term maintenance of its benefits. Indeed, studies have shown that improvement/resolution of the symptoms will persist up to 20 years after the procedure in more than $60 \%$ of the patients. This long-term efficacy is not achieved with the other treatment options of PCOS (excepted lifestyle modifications when they are maintained through the years).[30] Debras et al. showed in 2020 in a retrospective study that ovarian drilling permits spontaneous pregnancy and has a long-term effect. The predictive factors for this effectiveness were a normal body mass index (BMI), an infertility period of less than three years, an AFC of less than 50, and an age of less than 35. [44]

\section{Third line of treatment: in vitro fertilization and in vitro maturation}

When the second-line treatment options have failed, more complex therapies should be proposed, mainly in vitro fertilization (IVF) and, more recently, in vitro maturation (IVM).

IVF protocols use the combined action of gonadotropins with gonadotropin-releasing hormone agonist and antagonist.

Complications of this technique are multiple pregnancies and OHSS. After ovulation, multiple luteinized cysts are present within the ovaries leading to larger ovaries with higher vascular permeability resulting in a third space because of the shift of the fluids. Estrogens, progesterone and local cytokines are released as a vascular endothelial growth factor which encourages vascular hyperpermeability. The creation of a third space can lead to hypovolemia, renal insufficiency, and death. Women with PCOS are predisposed to develop OHSS because of the high number of antral follicles. [30]

The IVF-associated high risk of OHSS and multiple pregnancies in women with PCOS may be avoided with the in vitro maturation (IVM) procedure. IVM involves a short duration of gonadotrophin stimulation without a trigger injection. [31] Oocytes are retrieved from smaller follicles than what is done in conventional IVF. Oocyte meiosis and maturation to metaphase II occurs in vitro. Particularly appealing for PCOS women, this technique is also an opportunity to minimize exposure to high E2 doses in women with breast cancer or with thrombophilia.[28]

\section{New treatments}

\section{Myoinositol}

Inositol is one of the therapeutic alternatives which has recently been investigated. [23] It acts as the first line of treatment. There are nine different stereoisomers of inositol. Myoinositol is widely found in nature in plants and animal tissues. D-chiro-inositol is the second common isomer. Inositol can be produced in human cells from glucose and is directly involved in insulin cellular signaling.[32] It acts as an intracellular second messenger to regulate hormones like TSH, FSH and insulin. Inositol plays different roles with these stereoisomers, one enhancing cell glucose transportation 
Annals of International Medical and Dental Research

E-ISSN: 2395-2822 | P-ISSN: 2395-2814

Vol-8, Issue-1 | January-February 2022

DOI: 10.53339 /aimdr.2022.8.1.30

Page no- 225-234 | Section- Research Article (Obstetrics and Gynecology)

through the stimulation of the glucosetransporter 4 (GLUT4) translocation to the cell membrane, a second one downregulating the release of free fatty acids from adipose tissue. D-chiro-inositol upregulates the pyruvate dehydrogenase enzyme leading to the production of adenosine triphosphate (ATP), glycogen synthesis and in the ovaries, regulating the insulin-induced androgen synthesis. Myoinositol and D-chiro-inositol promote the enzyme-inducing the conversion from glucose to glycogen.

Myoinositol modulates the activation of glucose utilization and glucose transporters and regulates glucose uptake and $\mathrm{FSH}$ signaling in the ovaries.

Administration of D-chiro-inositol has been proved to reduce insulin resistance. Inositol improves the metabolic profile of PCOS patients. Some studies report that the dose needed is $1 \mathrm{~g}$ D-chiro-inositol $+400 \mathrm{mcg}$ folic acid per day to reduce metabolic syndrome and to increase the glycemia/insulin ratio.[33] Regidor et al. studied the effect of combined treatment with $2 \times 2000 \mathrm{mg}$ myo-inositol and $2 \times 200 \mathrm{mcg}$ folic acid per day for 2 and 3 months. They suggested that a myo-inositol therapy in women with PCOS induced a better fertilization rate and better embryo quality. Therefore, the use of myo-inositol is recommended as an improvement in IVF protocols for patients with PCOS with a dose of $4000 \mathrm{mg}$ per day. [34]

Studies also demonstrated a role of inositol in metabolic disorders and human reproduction as in ovulation.[35] Pundir et al.[36] in their review, found that inositol supplementation appeared to increase the rates of ovulation and the frequency of menstrual cycles. Nevertheless, no studies found a better live birth rate.

\section{Limitations of the Study}

The present study was conducted in a very short period due to time constraints and funding limitations. The small sample size was also a limitation of the present study.

\section{CONCLUSIONS}

PCOS is a frequent syndrome and the most frequent cause of infertility. PCOS is defined as a syndrome with at least two of three of the Rotterdam criteria. A complete evaluation of the infertility is needed to exclude other causes of infertility. PCOS treatment is still controversial but three lines of therapies were discussed. The first line of treatment remains lifestyle modifications and bariatric surgeryassociated or not with metformin and myoinositol. Clomiphene citrate and letrozole are considered also as the first line of treatment. Gonadotrophin therapy and ovarian drilling are the second line of treatment. Nevertheless, the place of transvaginal hydrolaparoscopic ovarian drilling is still not well clarified. Further studies are necessary to encourage this technique. If the patient is still resistant to those therapies, a third-line of treatment is proposed as in vitro fertilization and in vitro maturation.

\section{Recommendation}

This study can serve as a pilot to a much larger research involving multiple centers that can provide a nationwide picture, validate regression models proposed in this study for 
Annals of International Medical and Dental Research

E-ISSN: 2395-2822 | P-ISSN: 2395-2814

Vol-8, Issue-1 | January-February 2022

DOI: $10.53339 /$ aimdr.2022.8.1.30

Page no- 225-234 | Section- Research Article (Obstetrics and Gynecology)

future use and emphasize points to ensure better management and adherence.

\section{Acknowledgements}

The wide range of disciplines involved in Treatment of Infertility in Women with Polycystic Ovary Syndrome research means

\section{REFERENCES}

1. Practice Committee of the American Society for Reproductive Medicine. Definitions of infertility and recurrent pregnancy loss: a committee opinion. Fertil Steril. 2013;99(1):63. doi: 10.1016/j.fertnstert.2012.09.023.

2. Pasquali R, Antenucci D, Casimirri F, Venturoli S, Paradisi R, Fabbri R, et al. Clinical and hormonal characteristics of obese amenorrheic hyperandrogenic women before and after weight loss. J Clin Endocrinol Metab. 1989;68(1):173-9. doi: 10.1210/jcem-68-1-173.

3. Thessaloniki ESHRE/ASRM-Sponsored PCOS Consensus Workshop Group. Consensus on infertility treatment related to polycystic ovary syndrome. Hum Reprod. 2008;23(3):462-77. doi: 10.1093/humrep/dem426.

4. Gibson-Helm ME, Lucas IM, Boyle JA, Teede HJ. Women's experiences of polycystic ovary syndrome diagnosis. Fam Pract. 2014;31(5):545-9. doi: 10.1093/fampra/cmu028.

5. Melo AS, Ferriani RA, Navarro PA. Treatment of infertility in women with polycystic ovary syndrome: approach to clinical practice. Clinics (Sao Paulo). 2015;70(11):765-769. doi:10.6061/clinics/2015(11)09

6. Sahmay S, Aydogan Mathyk B, Sofiyeva N, Atakul N, Azemi A, Erel T. Serum AMH levels and insulin resistance in women with PCOS. Eur J Obstet Gynecol Reprod Biol. 2018;224:159-164. doi: 10.1016/j.ejogrb.2018.03.007.

7. Artini PG, Obino MER, Sergiampietri C, Pinelli S, Papini F, Casarosa E, et al. PCOS and pregnancy: a review of available therapies to improve the outcome of pregnancy in women with polycystic ovary syndrome. Expert Rev Endocrinol Metab. 2018;13(2):87-98. doi: 10.1080/17446651.2018.1431122. that an Editors needs much assistance from referees in the evaluation of papers submitted for publication. I am very grateful to many colleagues for their thorough, helpful and usually prompt response to requests for their opinion and advice.

8. Kiddy DS, Hamilton-Fairley D, Bush A, Short F, Anyaoku V, Reed MJ, Franks S. Improvement in endocrine and ovarian function during dietary treatment of obese women with polycystic ovary syndrome. Clin Endocrinol (Oxf). 1992;36(1):105-11. doi: 10.1111/j.1365-2265.1992.tb02909.x.

9. Balen AH, Dresner M, Scott EM, Drife JO. Should obese women with polycystic ovary syndrome receive treatment for infertility? BMJ. 2006;332(7539):434-435. doi:10.1136/bmj.332.7539.434

10. Crosignani PG, Colombo M, Vegetti W, Somigliana E, Gessati A, et al. Overweight and obese anovulatory patients with polycystic ovaries: parallel improvements in anthropometric indices, ovarian physiology and fertility rate induced by diet. Hum Reprod. 2003;18(9):1928-32. doi: 10.1093/humrep/deg367.

11. Malik SM, Traub ML. Defining the role of bariatric surgery in polycystic ovarian syndrome patients. World J Diabetes. 2012;3(4):71-79. doi:10.4239/wjd.v3.i4.71

12. Escobar-Morreale HF, Santacruz E, Luque-Ramírez $\mathrm{M}$, et al. Prevalence of "obesity-associated gonadal dysfunction" in severely obese men and women and its resolution after bariatric surgery: A systematic review and meta-analysis. Hum Reprod Update. 2017;23(4):390-408.

13. Mahawar KK, Parmar C, Graham Y. One anastomosis gastric bypass: key technical features, and prevention and management of procedure-specific complications. Minerva Chir. 2019;74(2):126-136. doi: 10.23736/S0026-4733.18.07844-6. Epub 2018 Jul 18.

14. Arterburn DE, Telem DA, Kushner RF, Courcoulas AP. Benefits and Risks of Bariatric Surgery in Adults: A Review. JAMA. 2020;324(9):879-887. doi: 10.1001/jama.2020.12567.

15. Morley LC, Tang T, Yasmin E, et al. Insulinsensitising drugs (metformin, rosiglitazone,

232 
Annals of International Medical and Dental Research E-ISSN: 2395-2822 | P-ISSN: 2395-2814 Vol-8, Issue-1 | January-February 2022 DOI: 10.53339 /aimdr.2022.8.1.30 Page no- 225-234 | Section- Research Article (Obstetrics and Gynecology)

pioglitazone, D-chiro-inositol) for women with polycystic ovary syndrome, oligo amenorrhoea and subfertility. Cochrane Database Syst Rev. 2017;11(11):CD003053.

16.Legro RS, Barnhart HX, Schlaff WD, Carr BR, Diamond MP, Carson SA, et al; Cooperative Multicenter Reproductive Medicine Network. Clomiphene, metformin, or both for infertility in the polycystic ovary syndrome. $\mathrm{N}$ Engl J Med. 2007;356(6):551-66. doi: 10.1056/NEJMoa063971.

17. Johnson NP, Stewart AW, Falkiner J, Farquhar CM, Milsom S, Singh VP, et al; REACT-NZ (REproduction And Collaborative Trials in New Zealand), a multicentre fertility trials group. PCOSMIC: a multi-centre randomized trial in women with PolyCystic Ovary Syndrome evaluating Metformin for Infertility with Clomiphene. Hum Reprod. 2010;25(7):1675-83. doi: 10.1093/humrep/deq100. Epub 2010 Apr 30.

18. Kettel LM, Roseff SJ, Berga SL, Mortola JF, Yen SS. Hypothalamic-pituitary-ovarian response to clomiphene citrate in women with polycystic ovary syndrome. Fertil Steril. 1993;59(3):532-8.

19. Kerin JF, Liu JH, Phillipou G, Yen SS. Evidence for a hypothalamic site of action of clomiphene citrate in women. J Clin Endocrinol Metab. 1985;61(2):265-8. doi: 10.1210/jcem-61-2-265.

20.Kumar P, Sait SF. Luteinizing hormone and its dilemma in ovulation induction. J Hum Reprod Sci. 2011;4(1):2-7. doi: 10.4103/0974-1208.82351.

21.Dehbashi S, Parsanezhad ME, Alborzi S, Zarei A. Effect of clomiphene citrate on endometrium thickness and echogenic patterns. Int J Gynaecol Obstet. 2003;80(1):49-53. doi: 10.1016/s00207292(02)00341-7.

22.Zhao J, Zhang Q, Li Y. The effect of endometrial thickness and pattern measured by ultrasonography on pregnancy outcomes during IVF-ET cycles. Reprod Biol Endocrinol. 2012;10:100. doi: 10.1186/1477-7827-10-100.

23.Huang S, Du X, Wang R, Li R, Wang H, Luo L, et al. Ovulation induction and intrauterine insemination in infertile women with polycystic ovary syndrome: A comparison of drugs. Eur J Obstet Gynecol Reprod Biol. 2018;231:117-121. doi: 10.1016/j.ejogrb.2018.08.002.

24. Mejia RB, Summers KM, Kresowik JD, Van Voorhis BJ. A randomized controlled trial of combination letrozole and clomiphene citrate or letrozole alone for ovulation induction in women with polycystic ovary syndrome. Fertil Steril. 2019;111(3):571-578.e1. doi: 10.1016/j.fertnstert.2018.11.030.

25. Casper RF. Letrozole versus clomiphene citrate: which is better for ovulation induction? Fertil Steril. 2009;92(3):858-859.

https:// doi.org/10.1016/j.fertnstert.2007.03.094

26. Balen AH, Morley LC, Misso M, et al. The management of anovulatory infertility in women with polycystic ovary syndrome: an analysis of the evidence to support the development of global WHO guidance. Hum Reprod Update. 2016;22(6):687-708. https://doi.org/10.1093/humupd/dmw025

27.Helmy M, Saleh S, El-Khouly N, et al. Transvaginal needle versus laparoscopic ovarian drilling in drugresistant polycystic ovary syndrome: a randomized, controlled study. Menoufia Med J. 2019; 32(2):436440.

28. Weiss NS, Kostova E, Nahuis M, Mol BWJ, van der Veen F, van Wely M. Gonadotrophins for ovulation induction in women with polycystic ovary syndrome. Cochrane Database Syst Rev. 2019;1(1):CD010290. doi: 10.1002/14651858.CD010290.pub3.

29. Gjønnaess H. Late endocrine effects of ovarian electrocautery in women with polycystic ovary syndrome. Fertil Steril. 1998;69(4):697-701. https://doi.org/10.1016/s0015-0282(98)00006-5

30.Walls ML, Hart RJ. In vitro maturation. Best Pract Res: $\quad$ Clin Obstetr Gynaec. 2018;53:60-72. https://doi.org/10.1016/j.bpobgyn.2018.06.004

31. Fauser BCJM, Tarlatzis BC, Rebar RW, et al. Consensus on women's health aspects of polycystic ovary syndrome (PCOS): the Amsterdam ESHRE/ASRM-Sponsored 3rd PCOS Consensus Workshop Group. Fertil Steril. 2012;97(1):28-38.e25.

32. Laganà AS, Rossetti $P$, Sapia $F$, et al. Evidence-based and patient-oriented inositol treatment in polycystic ovary syndrome: changing the perspective of the disease. Int J Endocrinol Metab. 2017;15(1):e43695.

33. Atay V, Cam C, Muhcu M, et al. Comparison of letrozole and clomiphene citrate in women with polycystic ovaries undergoing ovarian stimulation. J Int Med Res. 2006;34(1):73-76.

34. Baillargeon JP, Iuorno MJ, Jakubowicz DJ, et al. Metformin therapy increases insulin-stimulated release of D-Chiro-inositol-containing inositolphosphoglycan mediator in women with 
Annals of International Medical and Dental Research

E-ISSN: 2395-2822 | P-ISSN: 2395-2814

Vol-8, Issue-1 | January-February 2022

DOI: 10.53339/aimdr.2022.8.1.30

Page no- 225-234 | Section- Research Article (Obstetrics and Gynecology)

polycystic ovary syndrome. J Clin Endocrinol Metab. 2004;89(1):242-249.

35. Pundir J, Psaroudakis D, Savnur P, et al. Inositol treatment of anovulation in women with polycystic ovary syndrome: a meta-analysis of randomised trials. BJOG. 2018;125(3):299-308.

36. Laffargue P, Gares R, Luscan R, et al. Syndrome de Stein-Leventhal d'origine congénitale probable guéri par résection cunéiforme des ovaires et cortisone; hyperplasie fonctionnelle du stroma ovarien [SteinLeventhal syndrome of probable congenital origin cured by cuneiform resection of ovaries \& cortisone; functional hyperplasia of the ovarian stroma]. Bull Fed Soc Gynecol Obstet Lang Fr. 1957;9(3):317-322.

37. Mitra S, Nayak PK, Agrawal S. Laparoscopic ovarian drilling: an alternative but not the ultimate in the management of polycystic ovary syndrome. J Nat Sci Biol Med. 2015;6(1):40-48.

38. Ferraretti AP, Gianaroli L, Magli $\mathrm{MC}$, et al. Transvaginal ovarian drilling: a new surgical treatment for improving the clinical outcome of assisted reproductive technologies in patients with polycystic ovary syndrome. Fertil Steril. 2001;76(4):812-816.

39. Giampaolino P, Morra I, Tommaselli GA, et al. Postoperative ovarian adhesion formation after ovarian drilling: a randomized study comparing conventional laparoscopy and transvaginal hydrolaparoscopy. Arch Gynecol Obstet. 2016;294(4):791-796.

40.Debras E, Fernandez H, Neveu ME, et al. Ovarian drilling in polycystic ovary syndrome: Long term pregnancy rate. Eur J Obstet Gynecol Reprod Biol X. 2019;4:100093.
41. Giampaolino P, De Rosa N, Della Corte L, et al. Operative transvaginal hydrolaparoscopy improve ovulation rate after clomiphene failure in polycystic ovary syndrome. Gynecol Endocrinol. 2018;34(1):3235.

42. Ezedinma NA, Phelps JY. Transvaginal hydrolaparoscopy. JSLS. 2012;16(3):461-465.

43. Lebbi I, Ben Temime R, Fadhlaoui A, et al. Ovarian drilling in PCOS: is it really useful? Front Surg. 2015;2:30.

44. Lemieux S, Lewis GF, Ben-Chetrit A, et al. Correction of hyperandrogenemia by laparoscopic ovarian cautery in women with polycystic ovarian syndrome is not accompanied by improved insulin sensitivity or lipid-lipoprotein levels. J Clin Endocrinol Metab. 1999;84:4278-4282.

45. Bordewijk EM, Ng KYB, Rakic L, et al. Laparoscopic ovarian drilling for ovulation induction in women with anovulatory polycystic ovary syndrome. Cochrane Database Syst Rev. 2020;2:CD001122.

46.Seow KM, Juan CC, Hwang JL, et al. Laparoscopic surgery in polycystic ovary syndrome: reproductive and metabolic effects. Semin Reprod Med. 2008;26(1):101-110.

47.Practice Committee of American Society For Reproductive M.Diagnostic evaluation of the infertile female: a committee opinion. Fertil Steril. 2012;98(2):302-307.

Source of Support: Nil, Conflict of Interest: None declared 